\title{
Environmental Efficiency of Apple Production in China: A Translog Stochastic Frontier Analysis
}

\author{
Xiuguang Bai, Ruhul Salim, and Harry Bloch
}

\begin{abstract}
This article estimates technical and environmental efficiencies using the stochastic frontier analysis with panel data of twenty-two main apple production provinces in China during 1992-2014. Results show that the environmental efficiency for pesticide input alone has lower mean value of 0.337 than environmental efficiency for the two environmentally detrimental inputs, pesticide and chemical fertilizer, which is 0.782. Furthermore, all efficiency scores have decreasing trends over time. Loess Plateau is more environmentally efficient than the Bohai bay region. Results of output elasticities show that chemical fertilizer has a mean value of 0.225 , which is higher than for material, labor, and pesticide input. Also, apple production in China experiences decreasing returns to scale. Finally, it is also discovered that labor and chemical fertilizer have a substitute relationship, while material and labor have a complementary relationship, as do chemical fertilizer and pesticide. The results from the study should prove useful for reallocating input resources and improving environmental efficiency.
\end{abstract}

Key Words: apple, environmental efficiency, stochastic frontier production function, technical efficiency

JEL Classifications: C23, L25, L60, Q12

The agriculture sector has always been a fundamental corner stone underpinning the Chinese economy. Chinese agricultural output has expanded substantially, but success has come at considerable environmental cost (Xiang, Jia, and Huang 2012), such as the total agricultural output vaule increased from 1,099.55 billion to 3,623.9 billion RMB during 1993-2004, while the corresponding environmental costs increased from 17.94 to 122.55 billion RMB (Li, Qiu, and Yin 2009). The contribution of chemical fertilizer and pesticide inputs to agriculture output growth has been estimated beyond 60 percent (Zhang, Zhang, and Ma 2007; Bai, Chen, and Huo 2015), but the usage levels of chemical fertilizer and pesticide are close to or over the soil maximum potential, environmental bearing capacity and demand for crop production. As a result, there is low efficiency of chemical fertilizer and pesticide use

\footnotetext{
Xiuguang Bai, College of Economics \& Management, Northwest A\&F University, Yangling, China. Ruhul Salim and Harry Bloch, School of Economics, Finance \& Property Curtin Business School, Curtin University, Perth, WA 6845, Australia. Correspondence: Professor Ruhul Salim, School of Economics, Finance \& Property, Curtin Business School, Curtin University, Perth, WA 6845, Australia. Email: ruhul.salim@cbs.curtin.edu.au
}

Agricultural and Resource Economics Review 48/2 (August 2019) 199-220

(C) The Author(s) 2019. This is an Open Access article, distributed under the terms of the Creative

Commons Attribution licence (http://creativecommons.org/licenses/by/4.0/), which permits unrestricted re-use, distribution, and reproduction in any medium, provided the original work is properly cited. 
(efficiency is around 30 percent, according to Ju et al. 2009 and Ma et al. 2014) and serious agricultural nonpoint source pollution (Chen, Song, and Xu 2015).

The first national survey of pollution sources in the year of 2010 in China shows that total agricultural chemical oxygen demand, total nitrogen, and total phosphorus emissions from agricultural production activities accounted for 43.7 percent, 57.2 percent, and 67.4 percent of total emissions, respectively, indicating that agricultural pollution has exceeded industrial pollution and become the largest source of pollution in China. Agricultural pollution will cause a series of environmental problems, such as water eutrophication (Edgardo and Robert 2018), groundwater pollution (Ma et al. 2018), loss of biodiversity (Muditha and Clevo 2017), soil acidification and consolidation (Guo et al. 2010; Sebnem 2017), which can threaten food safety, human health, and sustainable agricultural development (Wang and Shen, 2016).

With the increasing concern over environmental protection, environmental efficiency has been studied by many scholars, and two approaches for evaluating environmental efficiency have been developed. One approach is taking environmentally detrimental factors as undesired outputs, which was proposed by Pittman (1983) using the Tornqvist index to measure environmental performance. However, this method has the defect that it not only needs the shadow price of the undesired output, but also it can not distinguish the effects of different shadow prices across individual items. Färe et al. (1989) improves the model, and proposes a standard data envelopment analysis (DEA) model, considering the undesired output as an output variable.

Subsequently, Färe et al. $(1993,2007)$ develop a distance function to estimate environmental efficiency, while Tone (2004) proposes the slack-based model (SBM) considering undesired output for modifying the estimated biases of DEA models. Li et al. (2011) estimate the environmental efficiency of China's agriculture sector using the SBM model taking environmental detrimental factors, such as emissions quantity of nitrogen and phosphorus, as undesired output variables and shows an average environmental efficiency of 0.450 during 1979-2008. The result is higher than the average environmental efficiency value of 0.218 measured by Cui and Zhang (2014) using the agriculture production data of China during 1990-2011. Chen et al. (2015) estimate the environmental efficiency of China using output-oriented DEA, with the economic data treating waste water, solid, and gas as undesired outputs and shows an excellent average environmental efficiency of 1.084, with the environmental efficiency of the northwest region remarkably higher than the other regions in China. Piao and $\mathrm{Li}$ (2018) show the environmental efficiency of agriculture is 0.867 during 20042012 using a DEA model and taking carbon as the undesired output variable.

An alternative to the above methodology has been developed by treating undesired outputs as input variables to measure environmental efficiency (Cropper and Oates 1992; Haynes et al. 1993; Boggs, 1997; Reinhard et al. 1999). Haynes et al. (1993) and Reinhard et al. (1999) take undesired outputs as input variables and measure environmental efficiency using the ratio of the minimum possible undesired outputs to the observed outputs. This method is 
beneficial to practical applications, because it can calculate the efficiency of each environmentally detrimental factor, such as the total nitrogen surplus or the nitrate surplus, instead of evaluating the total influence of all factors. Lansink and Reinhard (2004) points out that this method is more appropriate when producers face a series of environmental constraints. For example, Reinhard et al. (1999) measure the environmental efficiency of Dutch dairy farms using the stochastic frontier analysis (SFA) model taking the undesired output of nitrate surplus as an input. Subsequently, Reinhard et al. (2000) compare the differences in environmental efficiencies with multiple environmentally detrimental variables measured by SFA and DEA models, concluding SFA is a desirable method for estimating environmental efficiency.

Zhang and Xue (2005) measure the environmental efficiency of China's vegetable production using this SFA method taking chemical fertilizer and pesticide as environmentally detrimental inputs, finding different vegetable varieties had different environmental efficiency ranging from 0.426 to 0.977 . Zhou et al. (2015) estimate the environmental efficiency of hog production in China by SFA taking the undesired output of nitrate surplus as an input, showing an average environmental efficiency of 0.672 with a declining trend over time. Feng and Wang (2016) estimate the environmental efficiency for pesticide input of agriculture production in China during 2002-2012. Tian and Wang (2016) analyze the environmental efficiency of agriculture in China during 2004 to 2012 taking nitrogen, phosphorus, and carbon as undesired outputs.

Our literature review identifies only a few studies of environmental efficiency focusing on cash crop agricultural production. Zhang et al. (2007) report that cash crops in China in 2005 accounted for more than 50 percent of the use of chemical fertilizer and pesticide, which are the main pollutants from agriculture production, while the related studies on cash crop has ignored the impact of production on the environment pollution (Guo et al. 2013; Bai et al. 2015). Therefore, it is mportant to extend the evaluation of the environmental efficiency of cash crop production, particularly because environmental efficiency may vary with different crop varieties (Zhang and Xue, 2005) and nonpoint source pollution has become more serious in rural areas. In this study, we estimate technical efficiency and environmental efficiency of apple production in China focusing on the excessive use of chemical fertilizer and pesticide. Apple is a traditional advantage high-value cash crop of China. In addition, China is the largest apple producer and consumer in the world (Bai et al. 2015). Our results provide evidence that can guide policies for improving environmental efficiency and reducing environmental pollution, thereby helping to build a resource conservative and environmentally friendly society through achieving sustainable development.

The rest of the study is organized as follows. The research methodology is presented in Methodology section, followed by data sources and description analysis in the Data Sources and Descriptive Statistics section. The Empirical Results section provides the estimated results and analysis of the technical efficiency and environmental efficiency of apple production. The Conclusion section ends the manuscript with a brief conclusion and a discussion of policy implications. 


\section{Methodology}

The SFA model developed in Reinhard et al. $(1999,2000)$ for dairy farming is adopted in this study for apple production as a result of the similiarities they share in pollution sources and has advantages over DEA for the purpose of accommodating the the random nature of agricultural production. First, SFA do not require data on undesired outputs in agriculture production, such as excessive nitrogen and phosphate, whose measures are difficult to obtain. Secondly, it can measure efficiency of individual environmentally detrimental inputs, such as chemical fertilizer and pesticide, rather than the comprehensive influence of all factors in production (Reinhard et al. 1999, 2000). Besides, the characteristics of agriculture production are more fit to SFA, as the pollution sources of agriculture production, such as chemical fertilizer and pesticide, are not only undesired outputs (caused by excessive use), but also important inputs for agriculture production.

The stochastic frontier production function following Battese and Coelli (1995) can be expressed as follows:

$$
y_{i t}=f\left(x_{i t}, t, \beta\right) \exp \left(v_{i t}-u_{i t}\right)
$$

where for all provinces indexed with a subscript $i$ and for all years indexed with a subscript $t$; $y_{i t}$ is the output; $x_{i t}$ is a vector of inputs including labor, fertilizer, pesticide, and other material; $\beta$ is a vector of parameters to be estimated; $v_{i t}$ is a random error and $v_{i t} \sim \mathrm{iid}\left(0, \sigma_{\mathrm{v}}^{2}\right) ; \mathrm{u}_{\mathrm{it}}$ denotes technical inefficiency in production process, which is presumed to be nonnegative and distributed independently of $\mathrm{v}_{\mathrm{it}}, \mathrm{u}_{\mathrm{it}} \sim \mathrm{iid}\left(\mathrm{m}_{\mathrm{it}}, \sigma_{\mathrm{u}}^{2}\right)$. Then technical efficiency can be expressed as:

$$
T E_{i t}=y_{i t} /\left(f\left(x_{i t}, t, \beta\right) \exp \left(v_{i t}\right)\right)=\exp \left(-u_{i t}\right)
$$

In this study, we use the translog production function, because it is flexible and provides a second-order approximation of any functional form. The stochastic frontier translog production function is specified as follows:

$$
\begin{aligned}
& \operatorname{lny}_{i t}=\beta_{0}+\beta_{1} \operatorname{lnar}_{i t}+\beta_{2} \operatorname{lnla}_{i t}+\beta_{3} \operatorname{lnfe}_{i t}+\beta_{4} \operatorname{lnpe}_{i t}+\beta_{5} \operatorname{lnma}_{i t}+\beta_{6} \operatorname{lnir}_{i t}+\beta_{7} t \\
& +\beta_{8}\left(\operatorname{lnar}_{i t}\right)^{2}+\beta_{9}\left(\operatorname{lnla}_{i t}\right)^{2}+\beta_{10}\left(\operatorname{lnfe} e_{i t}\right)^{2}+\beta_{11}\left(\operatorname{lnpe}_{i t}\right)^{2}+\beta_{12}\left(\operatorname{lnma}_{i t}\right)^{2} \\
& +\beta_{13}\left(\text { Inir }_{i t}\right)^{2}+\beta_{14} t^{2}+\beta_{15} \operatorname{lnar}_{i t} \operatorname{lnla}_{i t}+\beta_{16} \operatorname{lnar}_{i t} \operatorname{lnfe}_{i t}+\beta_{17} \text { Inar }_{i t} \operatorname{lnpe} e_{i t} \\
& +\beta_{18} \text { Inar }_{i t} \operatorname{lnma}_{i t}+\beta_{19} \text { Inar }_{i t} \text { Inir }_{i t}+\beta_{20} \text { Inla }_{i t} \operatorname{lnfe}_{i t}+\beta_{21} \text { Inla }_{i t} \operatorname{lnpe}_{i t} \\
& +\beta_{22} \operatorname{lnla}_{i t} \operatorname{lnma}_{i t}+\beta_{23} \operatorname{lnla}_{i t} \operatorname{lnir}_{i t}+\beta_{24} \operatorname{lnfe}_{i t} \ln \ln _{i t}+\beta_{25} \operatorname{lnfe}_{i t} \operatorname{lnm}_{i t} \\
& +\beta_{26} \text { Infe }_{i t} \text { Inir }_{i t}+\beta_{27} \text { Inpe }_{i t} \operatorname{lnma}_{i t}+\beta_{28} \operatorname{lnpe}_{i t} \operatorname{lnir}_{i t}+\beta_{29} \operatorname{lnma}_{i t} \operatorname{lnir}_{i t}+\beta_{30} \text { tlnar }_{i t} \\
& +\beta_{31} \text { tlnla }_{i t}+\beta_{32} \text { tlnfe }_{i t}+\beta_{33} \text { tlnpe }_{i t}+\beta_{34} \text { tlnma }_{i t}+\beta_{35} \text { tlnir }_{i t}+v_{i t}-u_{i t}
\end{aligned}
$$


where $y_{i t}$ is the apple yield of i province in t year; $\mathrm{I}=1,2, \ldots, 22$ refers to main apple production provinces in China; $t=1,2, \ldots, 25$ denotes the year from 1992 to 2016; $\mathrm{ar}_{\text {it }}$ is the apple planting area input; $\mathrm{la}_{\mathrm{it}}$ is the labor input for apple production; $\mathrm{fe}_{\mathrm{it}}$ is the chemical fertilizer input for apple production, which is measured in terms of active ingredients by adding pure nitrogen, phosphate and potassium; $\mathrm{pe}_{i t}$ is the chemical pesticide input; $\mathrm{ma}_{\mathrm{it}}$ is machine input; $\mathrm{ir}_{\mathrm{it}}$ is irrigation area input for apple production; $t$ denotes time trend, which captures Hicksian technical progress.

According to Reinhard et al. (1999), environmental efficiency ( $\left.E_{i t}\right)$ is defined as the ratio of minimum feasible of environmentally detrimental input $\left(Z_{\mathrm{it}}^{\mathrm{o}}\right)$ to the observed value $\left(\mathrm{Z}_{\mathrm{it}}\right)$, other things being equal. Symbolically:

$$
\mathrm{EE}_{i t}=\min \left\{\theta_{i t}: f\left(x_{i t}, z_{i t}^{o} ; \beta\right)=f\left(x_{i t}, \theta_{i t} z_{i t} ; \beta\right) \geq y_{i t}\right\} \leq 1
$$

Treating chemical pesticide as the only environmentally detrimental input, the logarithm of the output of an environmentally efficient producer is obtained by replacing $\mathrm{pe}_{\mathrm{it}}$ with $\theta_{\mathrm{it}} \mathrm{pe}_{\mathrm{it}}$ and setting $\mathrm{u}_{\mathrm{it}}=0$ in equation (3) to obtain:

$$
\begin{aligned}
& \operatorname{lny}_{i t}=\beta_{0}+\beta_{1} \operatorname{lnar}_{i t}+\beta_{2} \operatorname{lnla}_{i t}+\beta_{3} \operatorname{lnfe}_{i t}+\beta_{4} \ln \theta_{i t} p e_{i t}+\beta_{5} \operatorname{lnma}_{i t}+\beta_{6} \operatorname{lnir}_{i t}+\beta_{7} t \\
& +\beta_{8}\left(\operatorname{lnar}_{i t}\right)^{2}+\beta_{9}(\operatorname{lnla} i t)^{2}+\beta_{10}\left(\operatorname{lnf} e_{i t}\right)^{2}+\beta_{11}\left(\ln \theta_{i t} p e_{i t}\right)^{2}+\beta_{12}\left(\operatorname{lnm} a_{i t}\right)^{2} \\
& +\beta_{13}\left(\operatorname{lnir}_{i t}\right)^{2}+\beta_{14} t^{2}+\beta_{15} \operatorname{lnar}_{i t} \operatorname{lnla}_{i t}+\beta_{16} \operatorname{lnar}_{i t} \ln f e_{i t}+\beta_{17} \operatorname{lnar}{ }_{i t} \ln \theta_{i t} p e_{i t} \\
& +\beta_{18} \operatorname{lnar}_{i t} \operatorname{lnma}_{i t}+\beta_{19} \operatorname{lnar}_{i t} \operatorname{lnir}_{i t}+\beta_{20} \operatorname{lnla}_{i t} \operatorname{lnf} e_{i t}+\beta_{21} \operatorname{lnla}_{i t} \ln \theta_{i t} p e_{i t} \\
& +\beta_{22} \text { Inla }_{i t} \operatorname{lnma}_{i t}+\beta_{23} \operatorname{lnla}_{i t} \operatorname{lnir}_{i t}+\beta_{24} \operatorname{lnfe}_{i t} \ln \theta_{i t} p e_{i t}+\beta_{25} \operatorname{lnfe}_{i t} \operatorname{lnma}_{i t} \\
& +\beta_{26} \operatorname{lnfe}_{i t} \operatorname{lnir}_{i t}+\beta_{27} \ln \theta_{i t} p e_{i t} \operatorname{lnm} a_{i t}+\beta_{28} \ln \theta_{i t} p e_{i t} \operatorname{lnir}_{i t}+\beta_{29} \operatorname{lnma}_{i t} \operatorname{lnir}_{i t} \\
& +\beta_{30} \text { tlnar }_{i t}+\beta_{31} \text { tlnla }_{i t}+\beta_{32} \text { tlnfe }_{i t}+\beta_{33} \operatorname{tln} \theta_{i t} p e_{i t}+\beta_{34} t \operatorname{lnm} a_{i t} \\
& +\beta_{35} \text { tlnir }_{i t}+v_{i t}
\end{aligned}
$$

According to the definition of environmental efficiency, $\ln E E_{i t}=\ln \frac{z_{i t}^{o}}{z_{i t}}=$ $\ln \frac{\theta_{i t} z_{i t}}{z_{i t}}=\ln \theta_{i t}$, so subtracting equation (3) from equation (5), we obtain:

$$
\begin{aligned}
\beta_{11}\left(\ln \theta_{i t}\right)^{2} & +\left(\beta_{4}+\beta_{17} \operatorname{lnar}_{i t}+\beta_{21} \operatorname{lnla}_{i t}+\beta_{24} \operatorname{lnfe}_{i t}+\beta_{27} \operatorname{lnma}_{i t}\right. \\
& \left.+\beta_{28} \operatorname{lnir}_{i t}+\beta_{33} t+2 \beta_{11} \operatorname{lnpe} e_{i t}\right) \ln \theta_{i t}+u_{i t}=0
\end{aligned}
$$

The unknown $\ln \theta_{i t}$ in equation (6) and hence $\mathrm{EE}_{i \mathrm{t}}$ can be solved from equation (6) as:

$$
E E_{i t}=\theta_{i t}=\exp \left\{\frac{-\lambda_{i t} \pm \sqrt{\lambda_{i t}^{2}-4 \beta_{11} u_{i t}}}{2 \beta_{11}}\right\}
$$


where

$$
\begin{aligned}
\lambda_{i t} & =\frac{\partial \operatorname{lny}_{i t}}{\partial \operatorname{lnp} e_{i t}}=\beta_{4}+\beta_{17} \operatorname{lnar}_{i t}+\beta_{21} \operatorname{lnla}_{i t}+\beta_{24} \operatorname{lnfe}_{i t}+\beta_{27} \operatorname{lnma}_{i t} \\
& +\beta_{28} \operatorname{lnir}_{i t}+\beta_{33} t+2 \beta_{11} \operatorname{lnpe}_{i t}
\end{aligned}
$$

$\lambda_{\text {it }}$ is known as the chemical pesticide output elasticity in the translog production function. The output elasticity of other input factors could be calculated using the same method.If we take chemical fertilizer and pesticide as two environmentally detrimental inputs and use the same process as above, we can obtain:

$$
\begin{aligned}
\left(\beta_{10}\right. & \left.+\beta_{11}+\beta_{24}\right)\left(\ln \theta_{i t}\right)^{2}+\left(\beta_{3}+\beta_{4}+\beta_{16} \operatorname{lnar}_{i t}+\beta_{17} \operatorname{lnar}_{i t}\right) \\
& +\beta_{20} \operatorname{lnla}_{i t}+\beta_{21} \operatorname{lnla}_{i t}+\beta_{24} \operatorname{lnfe}_{i t}+\beta_{24} \operatorname{lnpe}_{i t}+\beta_{25} \operatorname{lnma}_{i t} \\
& +\beta_{26} \operatorname{lnir}_{i t}+\beta_{27} \operatorname{lnma}_{i t}+\beta_{28} \operatorname{lnir}_{i t}+\beta_{32} t+\beta_{33} t+2 \beta_{10} \operatorname{lnfe}_{i t} \\
& \left.+2 \beta_{11} \operatorname{lnpe} \operatorname{lit}_{i t}\right) \ln \theta_{i t}+u_{i t}=0
\end{aligned}
$$

Thus, the $\mathrm{EE}_{\mathrm{it}}$ can be solved from equation (9) as:

$$
E E_{i t}=\exp \left\{\frac{-\lambda_{i t} \pm \sqrt{\lambda_{i t}^{2}-4\left(\beta_{10}+\beta_{11}+\beta_{24}\right) u_{i t}}}{2\left(\beta_{10}+\beta_{11}+\beta_{24}\right)}\right\}
$$

where

$$
\begin{aligned}
\lambda_{i t} & =\frac{\partial \operatorname{lny}_{i t}}{\partial \operatorname{lnfer}_{i t}}+\frac{\partial \operatorname{lny}_{i t}}{\partial \operatorname{lnpe} e_{i t}}=\beta_{3}+\beta_{4}+\beta_{16} \operatorname{lnar}_{i t}+\beta_{17} \operatorname{lnar}_{i t}+\beta_{20} \operatorname{Inla}_{i t} \\
& +\beta_{21} \operatorname{lnla}_{i t}+\beta_{24} \operatorname{lnfe}_{i t}+\beta_{24} \operatorname{lnpe}_{i t}+\beta_{25} \operatorname{lnm}_{i t}+\beta_{26} \operatorname{lnir}_{i t} \\
& +\beta_{27} \operatorname{lnma}_{i t}+\beta_{28} \operatorname{lnir}_{i t}+\beta_{32} t+\beta_{33} t+2 \beta_{10} \operatorname{lnfe}_{i t}+2 \beta_{11} \operatorname{lnpe}_{i t}
\end{aligned}
$$

$\lambda_{\text {it }}$ is then the sum of the output elasticities with respect to the environmentally detrimental inputs. Although there are two solutions in each of equation (7) and equation (10), only the " $+\sqrt{ }$ " is applied to estimate the environmental efficiency (Reinhard et al. 1999).

\section{Data Source and Descriptive Statistics}

In this study, we analyse the environmental efficiency of apple production using the dataset of 22 major apple production provinces in China during 1992-2016. Provincial panel data are used because two reasons. First, panel data analyze environmental efficiency from both the provincial and time-series aspects, thereby avoiding the drawback of limited availability of farm-level data (Zhou et al. 2015). Second, as the provincial data are averaged over individual 
farms, random disturbances across the provincial data are relatively small compared with those across individual farms.

Apple production is one of the highest value cash crops in China. The production of apple consumes large amounts of chemical products, such as chemical fertilizer and pesticide, which cause agricultural nonpoint source pollution. The quantity and efficiency of chemical fertilizer and pesticide use in apple production have potentially large effects on the environment and human health. So in this study, we examine the efficiency of use of chemical fertilizer and pesticide as two environmentally detrimental inputs in China's apple production.

The dataset used in the production frontier function is taken from the China Rural Statistical Yearbook (CRSY, NBSC 1993-2017) and China Statistical Yearbook (CSY, NBSC 1993-2017), which are issued by the National Bureau of Statistics of China (NBSC). These data have been used in several other studies (e.g., Shi et al. 2015; Zhou et al. 2015). The dataset includes apple yields, apple planting area, labor inputs, chemical fertilizer inputs, pesticide fees, irrigation area, and machine inputs in 22 main apple production provinces. Each variable in the dataset is measured for each farming season, which is 1 year for apple production. The descriptive statistics of the variables are presented in Table 1.

As seen in Table 1, the average apple yield in each province during 19922016 is $1152.84 \mathrm{kt}$, with a range from 3.05kt to $11007.82 .18 \mathrm{kt}$. Average apple planting area in each province is $102.36 \mathrm{kha}$, with minimum $0.10 \mathrm{kha}$ and maximum $704.80 \mathrm{kha}$. The labor input in each province varies widely from a minimum value of 0.12 to a maximum of 5412.66 thousand people, with an average of 214.91 thousand people. Average chemical fertilizer input in each province is equal to $35.10 \mathrm{kt}$, on a scale from 0.00 to $739.89 \mathrm{kt}$. Pesticide input is $0.808 \mathrm{kt}$ on average, with minimum and maximum input amounts of 0.00 and $16.674 \mathrm{kt}$, respectively. Such a large range of variation in chemical fertilizer and pesticide use might be induced by the different technology level and prices as well as variation in the natural resource and farmers' production behavior or risk attitudes across provinces. Machine input also has a great variation from a minimum of $0.1 \mathrm{mw}$ to a maximum of $7332.2 \mathrm{mw}$ during the research period, with an average of $549.2 \mathrm{mw}$, which may be influenced by the geographical conditions. The terrain of the Old Yellow River Course is relatively flat for apple production, which is very suitable for mechanization and more machines used, while the machines are few used in the gully hilly area of Loess Plateau and Southwest Cold Heights for the apple production. So the terrain is one of the important factors that affect the use of machines.

\section{Empirical Results}

The model specification for production frontier functional form is first tested using the likelihood-ratio statistic method. The results are presented in 
Table 1. Descriptive Statistics of Input and Output Variables in Each Province

\begin{tabular}{|c|c|c|c|c|c|c|c|}
\hline Variable & Yield(kt) & $\begin{array}{c}\text { Planting } \\
\text { Area } \\
\text { (kha) }\end{array}$ & $\begin{array}{l}\text { Labor } \\
\text { (10tp) }\end{array}$ & $\begin{array}{c}\text { Fertilizer } \\
\text { (kt) }\end{array}$ & $\begin{array}{c}\text { Pesticide } \\
\text { (0.1kt) }\end{array}$ & $\begin{array}{c}\text { Machine } \\
(10 \mathrm{mw})\end{array}$ & $\begin{array}{c}\text { Irrigation } \\
\text { (kha) }\end{array}$ \\
\hline Mean & 1152.84 & 102.36 & 21.49 & 35.10 & 8.08 & 54.92 & 41.36 \\
\hline Std.Dev & 2030.65 & 144.84 & 42.33 & 65.23 & 14.91 & 92.55 & 71.64 \\
\hline Min. & 3.05 & 0.10 & 0.01 & 0.00 & 0.00 & 0.01 & 0.01 \\
\hline Max. & 11007.82 & 704.80 & 541.27 & 739.89 & 166.74 & 733.22 & 963.73 \\
\hline
\end{tabular}

Table 2. Model Specification Tests

\begin{tabular}{|c|c|c|c|c|}
\hline Null Hypothesis & $\begin{array}{c}\text { LR } \\
\text { Value }\end{array}$ & $\begin{array}{c}\text { Degree of } \\
\text { Freedom(k) }\end{array}$ & $\begin{array}{c}\text { Threshold } \\
\mathbf{X}_{\mathbf{0 . 0 5}}^{2}(\mathbf{k})\end{array}$ & Decision \\
\hline$\gamma=0$ & 29.66 & 1 & 2.71 & Reject \\
\hline $\begin{array}{l}\text { C-D production function } \mathrm{H}_{0}: \beta_{8}=\beta_{=\ldots=}= \\
\quad \beta_{35}=0\end{array}$ & 178.46 & 29 & 41.98 & Reject \\
\hline $\begin{array}{l}\text { No technical progress } \mathrm{H}_{0}: \beta_{7}=\beta_{14=} \\
\quad \beta_{30=} \beta_{31}=\ldots=\beta_{35}=0\end{array}$ & 169.86 & 8 & 14.85 & Reject \\
\hline $\begin{array}{l}\text { Non-neutral technical progress } \mathrm{H}_{0} \text { : } \\
\quad \beta_{30=} \beta_{31}=\ldots=\beta_{35}=0\end{array}$ & 36.43 & 6 & 11.91 & Reject \\
\hline
\end{tabular}

Table 2. The first hypothesis test s pesticide, and hows $\gamma$ is significant at the level of 5 percent, which implies there is technical inefficiency in apple production so that the stochastic frontier approach is justified. The second hypothesis test shows that the translog production function is preferred to Cobb-Douglas form at the 5 percent significance level. The third and fourth hypothesis tests show that technical progress exists and is nonneutral, so the translog form with the time and other variables interacted with time is the preferred specification for estimation. Further testing with the Hausman test shows the fixed effects model is preferred to the random effects model, so the fixed effects stochastic frontier production function is estimated. Estimation is carried out using Stata 12.0 and the results are showed in Table 3, including the value and probability for the Hausman test.

As seen in Table 3, the coefficients of area and irrigation inputs are positive and significant at the confidence level of 1 percent, and the significant negative coefficient of quadratic area means the impact of area input on yield has an inverted U shape. Labor, fertilizer, and pesticide inputs each have significant negative coefficients, labor and fertilizer inputs have also an significant negative quadratic effects on yields, while machine input has a significant $U$ shape effect on apple yield. The sign of the coefficient on a variable for the 
Table 3. Estimation Results

\begin{tabular}{|c|c|c|c|c|c|}
\hline Variable & Coefficient & S.E. & Variable & Coefficient & S.E. \\
\hline $\operatorname{Area}\left(\beta_{1}\right)$ & $2.844^{* * *}$ & 0.676 & Labor*fertilizer $\left(\beta_{20}\right)$ & $0.659^{* * *}$ & 0.210 \\
\hline Labor $\left(\beta_{2}\right)$ & $-1.474^{* * *}$ & 0.403 & Labor*pesticide $\left(\beta_{21}\right)$ & -0.006 & 0.108 \\
\hline Fertilizer $\left(\beta_{3}\right)$ & $-2.090^{* * *}$ & 0.563 & Labor*machine $\left(\beta_{22}\right)$ & $-0.601^{* * *}$ & 0.188 \\
\hline Pesticide $\left(\beta_{4}\right)$ & $-0.134^{* * *}$ & 0.062 & Labor*irrigaiton $\left(\beta_{23}\right)$ & $0.873^{* * *}$ & 0.219 \\
\hline Machine $\left(\beta_{5}\right)$ & 0.223 & 0.475 & Fertilizer*pesticide $\left(\beta_{24}\right)$ & 0.129 & 0.113 \\
\hline Irrigation $\left(\beta_{6}\right)$ & $2.144^{* * *}$ & 0.560 & Fertilizer*machine $\left(\beta_{25}\right)$ & $0.457^{*}$ & 0.251 \\
\hline $\operatorname{time}\left(\beta_{7}\right)$ & $0.134^{* * *}$ & 0.037 & Fertilizer*irrigation $\left(\beta_{26}\right)$ & $1.349^{* * *}$ & 0.266 \\
\hline Quadratic area $\left(\beta_{8}\right)$ & $-0.277^{* *}$ & 0.130 & Pesticide*machine $\left(\beta_{27}\right)$ & -0.077 & 0.141 \\
\hline Quadratic labor $\left(\beta_{9}\right)$ & $-0.655^{* * *}$ & 0.134 & Pesticide*irrigation $\left(\beta_{28}\right)$ & $-0.296^{* * *}$ & 0.111 \\
\hline Quadratic fertilizer $\left(\beta_{10}\right)$ & $-1.174^{* * *}$ & 0.192 & Machine*irrigation $\left(\beta_{29}\right)$ & $-1.888^{* * *}$ & 0.361 \\
\hline Quadratic pesticide $\left(\beta_{11}\right)$ & 0.018 & 0.034 & $\operatorname{Time}{ }^{*} \operatorname{area}\left(\beta_{30}\right)$ & -0.023 & 0.015 \\
\hline Quadratic machine $\left(\beta_{12}\right)$ & $0.778^{* * *}$ & 0.190 & Time*labor $\left(\beta_{31}\right)$ & -0.013 & 0.011 \\
\hline Quadratic irrigation $\left(\beta_{13}\right)$ & 0.321 & 0.233 & Time*fertilizer $\left(\beta_{32}\right)$ & $0.038^{* * *}$ & 0.013 \\
\hline Quadratic time $\left(\beta_{14}\right)$ & 0.000 & 0.001 & Time*pesticide $\left(\beta_{33}\right)$ & $0.018^{* * *}$ & 0.007 \\
\hline Area*labor $\left(\beta_{15}\right)$ & $0.439^{* * *}$ & 0.161 & Time*machine $\left(\beta_{34}\right)$ & $-0.090^{* * *}$ & 0.015 \\
\hline Area*fertilizer $\left(\beta_{16}\right)$ & 0.384 & 0.268 & Time*irrigation $\left(\beta_{35}\right)$ & $0.068^{* * *}$ & 0.017 \\
\hline Area*pesticide $\left(\beta_{17}\right)$ & $0.248^{*}$ & 0.133 & Usigma & $-3.070^{* * *}$ & 0.124 \\
\hline Area*machine $\left(\beta_{18}\right)$ & $0.447^{* *}$ & 0.227 & Vsigma & $-3.926^{* * *}$ & 0.152 \\
\hline Area*irrigation $\left(\beta_{19}\right)$ & $-1.173^{* * *}$ & 0.311 & $\gamma$ & $0.702^{* * *}$ & 0.091 \\
\hline Hausman test & \multicolumn{3}{|c|}{ Chi-square $=52.06$} & \multicolumn{2}{|c|}{ P-value $=0.029$} \\
\hline
\end{tabular}

${ }^{*},{ }^{* *}$ and ${ }^{* * *}$ represent the significance levels of 10 percent, 5 percent, and 1 percent, respectively. 
interaction of two inputs indicates the direction of the effect use of each input has on the marginal productivity of the other. In Table 3, the coefficient of the interaction of area with labor, pesticide, and machine are each significantly positive, implying complementary relationships between area and labor, pesticide, and machine. In other words, more planting area input raises the productivity of labor, pesticide, and machine inputs, results that are easy to understand.

However, planting area and irrigation have a significant substitute relationship. The coefficients of interaction of labor with fertilizer and irrigation are each significantly positive, which imply complementary relationships between labor and fertilizer and irrigation. In other words, more fertilizer and irrigation increase the productivity of labor. However, labor and machine have a significant substitute relationship. The coefficients of the interaction of fertilizer with machine and irrigation are each significantly positive, which indicate they are complements so more machine use or irrigation improves fertilizer productivity. In contrast, irrigation has significant substitute relationships with both pesticide and machine. In other words, more irrigation input lowers the productivity of pesticide and machine input. Because unreasonable irrigation will greatly increase pesticide leaching, which decreases the productivity of pesticide. While mechanical farming can maintain soil moisture, which indicates the alternative relationship between irrigation and machine.

The coefficient of time in Table 3 is positive and significant, which indicates that apple production has experienced significant technical progress. Further, the coefficients of the interaction of time with input variables except for area and labor are all significant at the significance level of 1 percent, which indicates that the technical progress is not Hicks neutral (results are similar to Guo et al. 2013). The coefficients of the interaction of time and fertilizer, pesticide, and irrigation are all significantly positive, which indicates technical progresses increases with the use of these inputs and that the marginal contribution of these inputs has been increasing over time. In contrast, the interaction of time and machine has significant substitute relationship, which indicates technical progresses decreases with the use of machine and that the marginal contribution of machine has been decreasing over time. This is consistent with the trend of apple production shifting to dwarf dense planting production mode, which can save labor and machine, and reduce the pressure on machinery that is not suitable for the apple production in small-scale complex terrain. Meanwhile, the result is consistent to the results that the output elasticity of machine has a decreasing trend.

\section{Output Elasticity of Each Input}

Output elasticity of each input over time: Figure 1 reports the output elasticity with respect to each input from 1992 to 2016. These are calculated as indicated for the example of the output elasticity for pesticide in equation 


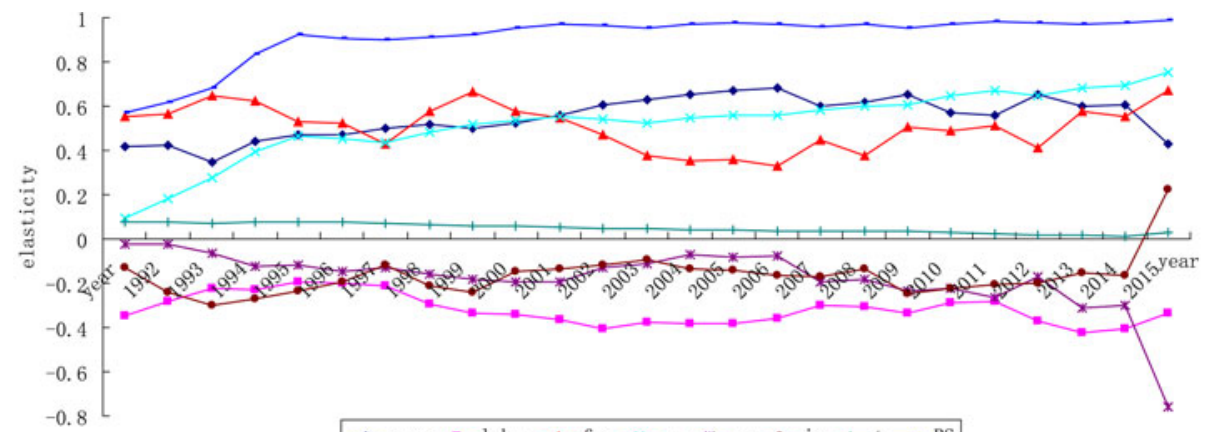

Figure 1. Output elasticity of each input over time

(8), with the coefficients in Table 3 used as estimates of the various beta parameters. The reported elasticity in each case is the average over all provinces.

Planting area has the highest average positive elasticity during the research period, followed by pesticide and fertilizer. The average output elasticity of planting area is 0.548, although decreasing in recent years. The average output elasticity of pesticide is 0.520 , with an increasing trend from 0.094 in 1992 to 0.752 in 2016 that indicates pesticide input has become increasingly important to apple production. Fertilizer has an average output elasticity of 0.51, which varies over the years without a clear trend. Shi et al. (2015) show that increasing chemical fertilizer prices has significantly reduced actual chemical fertilizer inputs, so a high output elasticity for fertilizer suggests finding a substitute for fertilizer is important to maintaining the level of apple output in China. The output elasticities of labor and machine are each negative, with the mean value of -0.319 and -0.179 , respectively. which suggests the excessive use of labor and machinery in apple production. The output elasticity of irrigation also is generally negative and has a mean value of -0.166 , although it turns positive in the latest year of 2016. The output elasticity of labor fluctuates with a characteristic of $\mathrm{W}$ shape, while that of machine has a decreasing trend with a sharp drop in 2016.

Now, we turn to returns to scale (RS) over time and technical progress. The estimate of returns to scale in each year is calculated as the sum of the elasticities for each of the inputs in that year. The mean sum of output elasticities for six input factors is 0.911 , with a continually increasing trend from 0.568 in 1992 to 0.987 in 2016. Apple production in China is close to the stage of constant returns to scale, especially since 2001, which means that apple production can be altered to meet demand through proportional changes in all inputs. The output elasticity of time, which provides an annual estimate for technical progress, is positive but generally declining with a mean value of 0.048 , which indicates a reduced contribution over time of technical progress to apple production in China. 
Regional output elasticity of each input: The average output elasticity with respect to each input for each of the 22 apple production provinces in China is calculated for the entire study period and shown in Table 4. There are similarities but also some substantial differences among the provinces and regions. First, the output elasticity with respect to planting area is positive in each province, except Inner Mongolia and Sinkiang provinces. Second, the output elasticity of labor in each province is negative, except Inner Mongolia, Jilin, Heilongjiang, Jiangsu, Hubei, and Sinkiang provinces, which implies the labor input is excessive in all but the excepted provinces.

Third, the output elasticity of fertilizer in each province is positive, except Tianjin, Jilin, Heilongjiang, Jiangsu, Anhui, Hubei, and Guizhou provinces, which suggests the fertilizer inputs are excessive in those provinces. Fourth, the output elasticity of pesticide is similar in all provinces, with the highest value in Beijing and lowest Jilin. Fifth, the output elasticity of machine in each province is negative except Beijing, Tianjin, Hebei, Shanxi, Jilin, Heilongjiang, Shandong, Qinghai, and Ningxia provinces. Sixth, the output elasticity of irrigation in each province is negative, except Jilin, Jiangsu, Anhui, Hubei, Sichuan, Guizhou, Yunnan, Tibet, and Sinkiang provinces. Seventh, the output elasticities with respect to time is positive in all provinces, except Qinghai province, which shows the technical progress of apple procduction in almost all the provinces. Finally, apple production has increasing returns to scale in Beijing, Tianjin, Jiangsu, Anhui, Hubei, and Guizhou provinces, while there are decreasing returns to scale in the other provinces.

By region, the average output elasticity of planting area in each region is positive, except for Sinkiang, with Southwest Cold Heights region having the highest output elasticity at a mean value of 1.067. The average output elasticity of labor is negative in Bohai Bay, Loess Plateau, and Southwest Cold Heights, which indicates the excessive input of labor. The average output elasticity of fertilizer in each region is positive, except for Southwest Cold Heights, while the average output elasticity of machine is negative, except for Bohai Bay. The elasticity of irrigation is negative, except for Bohai Bay and Loess Plateau. The output elasticity of time is positive in all regions. The highest value of 0.139 occurs in Sinkiang, meaning technical progress in Sinkiang is fastest among the regions.

\section{Technical and Environmental Efficiency in China}

Technical efficiency of apple production in China: Table 5 and Table 6 show the average technical efficiency as well as the environmental efficiency for both pesticide use alone and for pesticide and fertilizer use together in China from 1992 to 2016. Technical efficiency is calculated using equation (2). The average technical efficiency of apple production is 0.875 and ranges from 0.427 to 0.963 . This indicates farmers are on average achieving about 87.5 percent of best practice output in their use of inputs and technology, so that little output is sacrificed to inefficiency. However, there still is scope for more 
Table 4. Output Elasticity of Each Input over Provinces

\begin{tabular}{|c|c|c|c|c|c|c|c|c|c|}
\hline Region & Province & Area & Labor & Fertilizer & Pesticide & Machine & Irrigation & $\mathbf{t}$ & RS \\
\hline \multirow[t]{8}{*}{ Bohai Bay(Boh.Bay) } & Beijing & 0.877 & -0.103 & 0.006 & 0.735 & 0.243 & -0.407 & 0.050 & 1.352 \\
\hline & Tianjin & 0.718 & -0.115 & -0.021 & 0.656 & 0.646 & -0.660 & 0.017 & 1.223 \\
\hline & Hebei & 0.295 & -0.309 & 2.162 & 0.432 & 0.164 & -2.157 & 0.014 & 0.588 \\
\hline & Liaoning & 0.500 & -0.144 & 1.121 & 0.500 & -0.231 & -0.949 & 0.060 & 0.797 \\
\hline & Jilin & 0.700 & 0.310 & -1.084 & 0.390 & 0.113 & 0.552 & 0.078 & 0.980 \\
\hline & Heilongjiang & 0.212 & 0.571 & -0.175 & 0.405 & 0.150 & -0.518 & 0.062 & 0.644 \\
\hline & Shandong & 0.563 & -0.367 & 1.804 & 0.618 & 0.070 & -1.799 & 0.034 & 0.891 \\
\hline & mean & 0.552 & -0.022 & 0.545 & 0.534 & 0.165 & -0.848 & 0.045 & 0.925 \\
\hline \multirow[t]{4}{*}{ Yellow River Course(Yell.River) } & Jiangsu & 0.459 & 0.407 & -0.001 & 0.602 & -0.528 & 0.185 & 0.099 & 1.125 \\
\hline & Anhui & 0.895 & -0.406 & -0.010 & 0.458 & -0.251 & 0.317 & 0.067 & 1.002 \\
\hline & Inner Mongolia & -0.308 & 0.548 & 0.624 & 0.384 & -0.551 & -0.130 & 0.062 & 0.567 \\
\hline & mean & 0.349 & 0.183 & 0.204 & 0.482 & -0.444 & 0.124 & 0.076 & 0.898 \\
\hline \multirow[t]{7}{*}{ Loess Plateau(Loe. Plat.) } & Shanxi & 0.500 & -0.571 & 1.498 & 0.471 & 0.346 & -1.576 & 0.007 & 0.668 \\
\hline & Henan & 0.660 & -0.518 & 1.060 & 0.509 & -0.014 & -0.820 & 0.039 & 0.877 \\
\hline & Shaanxi & 0.166 & -0.325 & 1.131 & 0.496 & -0.418 & -0.279 & 0.046 & 0.771 \\
\hline & Gansu & 0.374 & -0.757 & 2.096 & 0.513 & -0.389 & -1.229 & 0.029 & 0.608 \\
\hline & Qinghai & 0.942 & -1.405 & 0.708 & 0.530 & 0.162 & -0.042 & -0.009 & 0.894 \\
\hline & Ningxia & 0.193 & -0.020 & 0.127 & 0.624 & 0.224 & -0.160 & 0.023 & 0.987 \\
\hline & mean & 0.473 & -0.599 & 1.103 & 0.524 & -0.015 & -0.684 & 0.022 & 0.801 \\
\hline \multirow[t]{6}{*}{ Southwest Cold Heights(S.W.) } & Hubei & 1.340 & 0.059 & -2.030 & 0.537 & -0.031 & 1.515 & 0.109 & 1.390 \\
\hline & Sichuan & 0.906 & -0.928 & 0.212 & 0.494 & -0.631 & 0.888 & 0.066 & 0.942 \\
\hline & Guizhou & 1.262 & -1.583 & -0.593 & 0.457 & -0.080 & 1.540 & 0.024 & 1.004 \\
\hline & Yunnan & 0.972 & -1.158 & 0.431 & 0.401 & -0.342 & 0.526 & 0.042 & 0.829 \\
\hline & Tibet & 0.853 & -1.699 & 1.201 & 0.558 & -0.682 & 0.753 & 0.005 & 0.984 \\
\hline & mean & 1.067 & -1.062 & -0.156 & 0.490 & -0.353 & 1.044 & 0.049 & 1.030 \\
\hline Sinkiang & Sinkiang(Sink.) & -1.038 & 1.536 & 0.942 & 0.660 & -1.914 & 0.705 & 0.139 & 0.891 \\
\hline
\end{tabular}


Table 5. Technical and Environmental Efficiency of Apple Production over Years

\begin{tabular}{|c|c|c|c|c|c|c|c|c|c|c|c|c|c|c|c|c|c|c|}
\hline \multirow[b]{2}{*}{ Year } & \multicolumn{6}{|c|}{$\mathbf{T E}$} & \multicolumn{6}{|c|}{ EE for Pesticide } & \multicolumn{6}{|c|}{ EE for Two Inputs } \\
\hline & $\begin{array}{l}\text { Boh. } \\
\text { Bay }\end{array}$ & $\begin{array}{l}\text { Yell. } \\
\text { River }\end{array}$ & $\begin{array}{l}\text { Loe. } \\
\text { Plat. }\end{array}$ & S.W & SinK. & Mean & $\begin{array}{l}\text { Boh. } \\
\text { Bay }\end{array}$ & $\begin{array}{c}\text { Yell. } \\
\text { River }\end{array}$ & $\begin{array}{l}\text { Loe. } \\
\text { Plat. }\end{array}$ & S.W & SinK. & Mean & $\begin{array}{l}\text { Boh. } \\
\text { Bay }\end{array}$ & $\begin{array}{c}\text { Yell. } \\
\text { River }\end{array}$ & $\begin{array}{l}\text { Loe. } \\
\text { Plat. }\end{array}$ & S.W & SinK & Mean \\
\hline 1992 & 0.903 & 0.815 & 0.800 & 0.910 & 0.885 & 0.863 & 0.496 & 0.037 & 0.459 & 0.576 & 0.062 & 0.326 & 0.740 & 0.773 & 0.841 & 0.685 & 0.843 & 0.776 \\
\hline 1993 & 0.890 & 0.782 & 0.873 & 0.844 & 0.484 & 0.775 & 0.492 & 0.047 & 0.485 & 0.644 & 0.098 & 0.353 & 0.751 & 0.760 & 0.901 & 0.596 & 0.669 & 0.735 \\
\hline 1994 & 0.886 & 0.731 & 0.850 & 0.852 & 0.924 & 0.849 & 0.543 & 0.255 & 0.484 & 0.533 & 0.275 & 0.418 & 0.721 & 0.754 & 0.879 & 0.644 & 0.921 & 0.784 \\
\hline 1995 & 0.894 & 0.820 & 0.870 & 0.866 & 0.946 & 0.879 & 0.613 & 0.252 & 0.549 & 0.643 & 0.281 & 0.468 & 0.753 & 0.803 & 0.891 & 0.661 & 0.950 & 0.812 \\
\hline 1996 & 0.898 & 0.858 & 0.884 & 0.762 & 0.936 & 0.868 & 0.614 & 0.356 & 0.566 & 0.603 & 0.326 & 0.493 & 0.774 & 0.810 & 0.899 & 0.580 & 0.936 & 0.800 \\
\hline 1997 & 0.894 & 0.873 & 0.886 & 0.835 & 0.929 & 0.883 & 0.591 & 0.478 & 0.603 & 0.712 & 0.424 & 0.562 & 0.790 & 0.833 & 0.916 & 0.602 & 0.923 & 0.813 \\
\hline 1998 & 0.902 & 0.891 & 0.899 & 0.836 & 0.900 & & & 0.531 & & & & & & 0.831 & & 0.569 & 0.899 & 0.798 \\
\hline 1999 & 0.896 & 0.911 & 0.914 & 0.880 & 0.918 & 0.904 & 0.598 & 0.593 & 0.641 & 0.703 & 0.578 & 0.623 & 0.817 & 0.858 & 0.886 & 0.703 & 0.930 & 0.839 \\
\hline 2000 & 0.887 & 0.921 & 0.912 & 0.871 & 0.927 & 0.904 & 0.584 & 0.615 & 0.648 & 0.688 & 0.592 & 0.625 & 0.841 & 0.872 & 0.923 & 0.694 & 0.940 & 0.854 \\
\hline 2001 & 0.877 & 0.906 & 0.891 & 0.863 & 0.894 & 0.886 & 0.677 & 0.562 & 0.605 & 0.694 & 0.783 & 0.664 & 0.836 & 0.832 & 0.903 & 0.664 & 0.908 & 0.829 \\
\hline 2002 & 0.884 & 0.899 & 0.886 & 0.886 & 0.868 & 0.885 & 0.665 & 0.564 & 0.607 & 0.729 & 0.505 & 0.614 & 0.858 & 0.830 & 0.899 & 0.669 & 0.886 & 0.828 \\
\hline 2003 & 0.887 & 0.889 & 0.892 & 0.899 & 0.859 & 0.885 & 0.680 & 0.584 & 0.627 & 0.768 & 0.253 & 0.582 & 0.832 & 0.791 & 0.909 & 0.653 & 0.868 & 0.811 \\
\hline 2004 & 0.900 & 0.902 & 0.868 & 0.895 & 0.856 & 0.884 & 0.626 & 0.654 & 0.624 & 0.775 & 0.133 & 0.562 & 0.766 & 0.811 & 0.893 & 0.657 & 0.860 & 0.797 \\
\hline 2005 & 0.899 & 0.891 & 0.875 & 0.900 & 0.863 & 0.886 & 0.629 & 0.659 & 0.620 & 0.797 & 0.062 & 0.553 & 0.791 & 0.792 & 0.893 & 0.667 & 0.861 & 0.801 \\
\hline 2006 & 0.898 & 0.898 & 0.859 & 0.870 & 0.852 & 0.875 & 0.644 & 0.699 & 0.635 & 0.785 & 0.267 & 0.606 & 0.783 & 0.796 & 0.876 & 0.662 & 0.847 & 0.793 \\
\hline 2007 & 0.883 & 0.892 & 0.845 & 0.859 & 0.858 & 0.867 & 0.637 & 0.701 & 0.639 & 0.755 & 0.347 & 0.616 & 0.754 & 0.785 & 0.868 & 0.670 & 0.848 & 0.785 \\
\hline 2008 & 0.891 & 0.873 & 0.852 & 0.825 & 0.858 & 0.860 & 0.661 & 0.671 & 0.669 & 0.678 & 0.451 & 0.626 & 0.775 & 0.784 & 0.888 & 0.695 & 0.845 & 0.797 \\
\hline 2009 & 0.897 & 0.886 & 0.851 & 0.908 & 0.873 & 0.883 & 0.706 & 0.715 & 0.669 & 0.804 & 0.545 & 0.688 & 0.772 & 0.795 & 0.892 & 0.678 & 0.888 & 0.805 \\
\hline 2010 & 0.880 & 0.870 & 0.850 & 0.892 & 0.823 & 0.863 & 0.678 & 0.690 & 0.661 & 0.705 & 0.460 & 0.639 & 0.767 & 0.796 & 0.887 & 0.721 & 0.869 & 0.808 \\
\hline 2011 & 0.888 & 0.902 & 0.854 & 0.894 & 0.863 & 0.880 & 0.702 & 0.770 & 0.669 & 0.802 & 0.593 & 0.707 & 0.768 & 0.832 & 0.897 & 0.728 & 0.895 & 0.824 \\
\hline 2012 & 0.887 & 0.905 & 0.853 & 0.865 & 0.896 & 0.881 & 0.705 & 0.787 & 0.670 & 0.764 & 0.692 & 0.724 & 0.779 & 0.842 & 0.890 & 0.728 & 0.921 & 0.832 \\
\hline 2013 & 0.866 & 0.880 & 0.846 & 0.842 & 0.933 & 0.873 & 0.698 & 0.738 & 0.708 & 0.772 & 0.770 & 0.737 & 0.751 & 0.844 & 0.876 & 0.705 & 0.939 & 0.823 \\
\hline
\end{tabular}




\begin{tabular}{lllllllllllllllllll}
2014 & 0.863 & 0.902 & 0.859 & 0.934 & 0.843 & 0.880 & 0.699 & 0.790 & 0.732 & 0.879 & 0.568 & 0.734 & 0.757 & 0.839 & 0.888 & 0.775 & 0.883 & 0.828 \\
2015 & 0.869 & 0.898 & 0.897 & 0.923 & 0.909 & 0.899 & 0.710 & 0.784 & 0.819 & 0.882 & 0.745 & 0.788 & 0.767 & 0.877 & 0.831 & 0.780 & 0.929 & 0.837 \\
2016 & 0.837 & 0.884 & 0.882 & 0.911 & 0.913 & 0.885 & 0.673 & 0.764 & 0.777 & 0.847 & 0.770 & 0.766 & 0.767 & 0.865 & 0.925 & 0.795 & 0.937 & 0.858 \\
Mean & 0.886 & 0.875 & 0.870 & 0.873 & 0.873 & 0.875 & 0.637 & 0.572 & 0.630 & 0.730 & 0.444 & 0.603 & 0.781 & 0.816 & 0.889 & 0.679 & 0.888 & 0.811 \\
\hline
\end{tabular}

Table 6. Technical and Environmental Efficiency of Apple Production over Regions and Provinces

\begin{tabular}{|c|c|c|c|c|c|c|c|c|c|}
\hline Region & Province & TE & $\begin{array}{c}\text { EE for } \\
\text { Pesticide }\end{array}$ & $\begin{array}{c}\text { EE for } \\
\text { Two } \\
\text { Inputs }\end{array}$ & Region & Province & TE & $\begin{array}{c}\text { EE for } \\
\text { Pesticide } \\
\end{array}$ & $\begin{array}{c}\text { EE for } \\
\text { Two } \\
\text { Inputs }\end{array}$ \\
\hline \multirow[t]{7}{*}{ BohaiBay } & Beijing & 0.876 & 0.403 & 0.747 & \multirow[t]{6}{*}{ Loess Plateau } & Shanxi & 0.870 & 0.679 & 0.928 \\
\hline & Tianjin & 0.893 & 0.479 & 0.673 & & Henan & 0.891 & 0.729 & 0.927 \\
\hline & Hebei & 0.894 & 0.622 & 0.956 & & Shaanxi & 0.883 & 0.773 & 0.929 \\
\hline & Liaoning & 0.888 & 0.744 & 0.930 & & Gansu & 0.893 & 0.751 & 0.955 \\
\hline & Jilin & 0.883 & 0.720 & 0.460 & & Qinghai & 0.817 & 0.286 & 0.808 \\
\hline & Heilongjiang & 0.882 & 0.722 & 0.755 & & Ningxia & 0.866 & 0.561 & 0.787 \\
\hline & Shandong & 0.888 & 0.728 & 0.947 & \multirow{4}{*}{$\begin{array}{l}\text { Southwest Cold } \\
\text { Heights }\end{array}$} & Hubei & 0.876 & 0.715 & 0.208 \\
\hline \multirow{3}{*}{$\begin{array}{l}\text { Yellow River } \\
\text { Course }\end{array}$} & Jiangsu & 0.876 & 0.637 & 0.792 & & Sichuan & 0.891 & 0.761 & 0.858 \\
\hline & Anhui & 0.867 & 0.628 & 0.784 & & Guizhou & 0.880 & 0.746 & 0.614 \\
\hline & $\begin{array}{l}\text { Inner } \\
\text { Mongolia }\end{array}$ & 0.883 & 0.486 & 0.873 & & Yunnan & 0.882 & 0.724 & 0.884 \\
\hline Sinkiang & Sinkiang & 0.873 & 0.497 & 0.888 & & Tibet & 0.836 & 0.376 & 0.833 \\
\hline
\end{tabular}


than a ten percent increase in apple production with the same inputs and technology, provided that technical inefficiency is completely eliminated. These results are similar to Guo et al. (2013), who show the average technical efficiency of apple production in China is 0.864 during 2001-2010.

Technical efficiencies in different regions and provinces generally are not notably different and have a similar fluctuating pattern over time. In detail, technical efficiencies in Sinkiang, Southwest Cold Heights and Yellow River Course fluctuates greatly, especially in the year of 1992-1997. And from then technical efficiencies show a small and stable fluctuation characteristics. By regions, technicial efficiency is highest in Bohai Bay, followed by Yellow River Course, which have the longest apple planting history. By provinces, Hebei has the highest techincial efficiency with an average value of 0.894 , followed by Tianjin and Gansu with an average value of 0.893 , which are all in Bohai Bay and Northwest Loess Plateau, the first two major apple production regions. While techincial efficiency in Qinghai is the lowest with an average value of 0.817 , which may be related with the production condition and climate factors. On a whole, technical efficiency of apple production in China still has room for improvement.

Environmental efficiency for pesticide input: Environmental efficiency for pesticide input is estimated using equation (7) and results are reported in Table 5 and Table 6. It can be seen that the environmental efficiency estimates for pesticide input are lower and have greater variability, ranging from 0.028 to 0.910 with an average value of 0.603 , than the corresponding estimates for technical efficiency, and have a positive relationship with technical efficiency. The low environmental efficiency indicates that the output value of apple could be maintained using observed values of other inputs while reducing 39.7 percent of the pesticide input. Therefore, there is a great potential for improving profitability and environmental impact of apple production by improving environmental efficiency and reducing the use of pesticide input in China.

Environmental efficiency for pesticide input has an obvious increasing trend during 1992-2016. The calculated average environmental efficiency increases from 0.326 in 1992 to 0.766 in 2016 and annual environmental efficiency improvement is 3.478 percent. This results may be related with the technical extension services of physical insecticide and biological pesticide. By regions, environmental efficiencies for pesticide input in different regions have a similar pattern of fluctuations around increasing trend, except for Sinkiang having pronounced fluctuations with an N shape from 1992 to 2016. Specifically, environmental efficiencies for pesticide input in Sinkiang, Yellow River Course and Southwest Cold Heights fluctuates greatly with a increasing trend during 1992-1997, which are similar to corresponding technical efficiency trends. And from then environmental efficiencies show small and stable fluctuation characteristics except Sinkiang, whose environmental efficiency decreased sharply from 0.783 in 2001to 0.062 in 2005, and then increased to 0.770 in 2016 in fluctuation. The region of largest improvement 
in environmental efficiency for pesticide is Yellow River Course area, which increased from 0.037 in 1992 to 0.764 in 2016. Average environmental efficiency for pesticide in Southwest Cold Heights is highest with an average value of 0.730, followed by Bohai Bay and Northwest Loess Plateau with average value of 0.637 and 0.630 , respectively, while the average environmental efficiency in Sinkiang is lowest at 0.444 . The results may be related with the climate factors, the low temperature in Southwest Cold Heights can reduce the occurrence of insect pests and reduce the use of pesticides, and then improve the environmental efficiencies for pesticide, while the situation is opposite to Sinkiang.

Table 6 shows the average environmental efficiencies for pesticide input across provinces. The highest average efficiency is 0.773 in Shaanxi province during 1992-2016, and the lowest average is 0.286 in Qinghai province, which are both in Northwest Loess Plateau, so the range of environmental efficiencies in Northwest Loess Plateau is bigger than in other regions. The second largest range across provinces is in the Southwest Cold Heights region, while the smallest range is in the Yellow River Course region. The results may be explained by the changes of terrain and climate conditions, the terrain and climate conditions are not suitable for the apple production in Qinghai and Tibet, which lead to their relatively lowest environmental efficiencies for pesticide input, and then expand the range of environmental efficiencies in corresponding regions. While the changes of terrain and climate conditions in Yellow River Course are small, so the range of environmental efficiency changes is the smallest in Yellow River Course region.

Our results are similar to those in Zhang and Xue (2005), Singbo et al. (2015), Abedullah et al. (2015), and Feng and Wang (2016). The first study finds the environmental efficiency for pesticide in vegetable production averages 0.69 , ranging from 0.049 to 0.948 with different vegetable varieties. The environmental efficiency of spinach is lowest with a value of 0.049 , and the highest is cucumber with 0.948 , and the efficiencies of pepper and garlic are 0.540 and 0.702 , respectively. Singbo et al. (2015) estimate pesticide use efficiency in vegetable production is 0.635 in southern Benin. Abedullah et al. (2015) find the environmental efficiency for pesticide of Bt cotton in Pakistan is 0.56. Feng and Wang (2016) show the environmental efficiency for pesticide input in agriculture production is 0.482 in China during 20022012. Thus, environmental efficiency for pesticide input for apple production in China is quite similar to previous econometric estimates for vegetable production, while it is little higher than for agriculture production in general. Natural scientists' research on the efficiencies of pesticides provide values of 0.2-0.3 in spring orchards and fields, rising to 0.5-0.6 in summer orchards and fields (Yuan et al. 2011).

Environmental efficiency for two environmental detrimental inputs: Environmental efficiencies for chemical pesticide and fertilizer together are estimated using equation (10), and presented in Table 5 and Table 6. The environmental efficiencies for chemical pesticide and fertilizer together are 
higher than corresponding environmental efficiencies for pesticide input alone, and lower than the corresponding technical efficiencies, while their correlation coefficiencts are all above 0.74 , which indicate they have a positive relationship. The average environmental efficiency for chemical and pesticide inputs together is 0.811 , with a minimum value 0.105 and maximum value 0.984 . Improving the average efficiency of chemical pesticide and fertilizer inputs to full efficiency would result in reducing their use by 18.9 percent together while producing the same output of apple with other observed inputs. The relatively higher environmental efficiency for both chemical pesticide and fertilizer inputs together results from attributing the shortfall from bestpractice output to two inputs rather than a single input, in effect spreading responsibility.

As it can be seen from Table 5, environmental efficiency for pesticide and fertilizer inputs together generally fluctuate in the $\mathrm{N}$ shape over time across the regions. Specifically, environmental efficiency for the two inputs together in almost all regions increase to the highest level in 2000, and then fall to the lowest level in 2007, and finally rise again to the highest level in 2016. The results may be related with the agricultural policy. The agricultural production focused on the grain crops before the year of 2000, so less pesticide and fertilizer used on the apple production; while the intensive agricultural production mode based on large investment in pesticides and fertilizers was implemented during 2000-2005, and the development model of fine agriculture and ecological agriculture based on science and technology was practiced sine 2006, which indirectly affected the environmental efficiency for pesticide and fertilizer inputs together.

In detail, environmental efficiencies for chemical pesticide and fertilizer inputs together in Sinkiang and Southwest Cold Heights fluctuates greatly during 1992-1999, which are similar to corresponding technical efficiency and environmental efficiencies for chemical pesticide input trends. And from then environmental efficiencies show small and stable fluctuation characteristics. The highest average environmental efficiency is 0.889 in Northwest Loess Plateau, followed by Sinkiang with a mean of 0.888 , while the lowest environmental efficiency is 0.679 in Southwest Cold Heights. Almost all the environmental efficiencies for pesticide and fertilizer inputs together are higher than environmental efficiencies for pesticide input alone in each region except Southwest Cold Heights. The results may be explained by the changes of soil fertility and climate conditions of the regions, soil fertility in Northwest Loess Plateau and Sinkiang is relatively high, which needs relatively lower chemical fertilizer and results in higher environmental efficiencies for pesticide and fertilizer inputs together, while the relatively poor soil in Southwest Cold Heights needs more fertilizer, which leads to lower environmental efficiency for pesticide and fertilizer inputs together than environmental efficiency for pesticide input alone.

As shown in Table 6, the average environmental efficiency for pesticide and fertilizer together inputs varies across provinces. The average highest 
efficiency over 1992-2016 is 0.956 in Hebei province and the average lowest is 0.208 in Hubei province. And almost all the environmental efficiencies for pesticide and fertilizer inputs together are higher than environmental efficiencies for pesticide input alone in each province except Hubei and Guizhou in the Southwest Cold Heights. These results may be explained by the same reason that soil fertility and climate conditions. The region having largest variation in environmental efficiency across provinces is Southwest Cold Heights, followed by Bohai Bay, while the smallest variation is in the Yellow River Course region. The results may be related with the changes of terrain, soil fertility and climate conditions.

Our results are similar to those of Zhang and Xue (2005), who estimate the environmental efficiency for both pesticide and chemical fertilizer of vegetable production in China with SFA and find environmental efficiency varies across vegetable varieties, ranging from 0.426 to 0.977 . The average environmental efficiencies of pepper and garlic are 0.731 and 0.848 , respectively, which are very close to our findings of the average environmental efficiency for the combination of pesticide and fertilizer inputs. However, our average environmental efficiency for the combined inputs is higher than the results in Li et al. (2011) and Tian and Wang (2016), but lower than the results in Piao and Li (2018). Li et al. (2011) find the average environmental efficiency of agriculture in China during 19792008 is 0.45 using the SBM model with nitrogen and phosphorus as environmentally damaging, while Tian and Wang (2016) find the average environmental efficiency of agriculture in China is 0.489 from 2004 to 2012 using SFA with nitrogen, phosphorus and carbon as environmentally damaging. Piao and $\mathrm{Li}$ (2018) show the environmental efficiency of agriculture is 0.867 during 2004-2012 with DEA model taking carbon as environmentally damaging. The difference in findings across studies of environmental efficiency may be partially due to different methods and crop characteristics, especially the differences between inputs or outputs treated as environmentally damaging, suggesting it is most appropriate to compare our findings to those of Zhang and Xue (2005).

\section{Conclusion}

In this study, a stochastic frontier translog production function is estimated using the panel data of 22 main apple production provinces in China during 1992-2016 to assess the technical efficiency and environmental efficiency of apple production in China. Estimates of output elasticity show that for increasing apple yield planting area is the most important input, followed by chemical pesticide and fertilizer input. The sum of output elasticities is less than one on average, showing that apple production in China exhibits decreasing returns to scale but with a rising trend that exhibits close to the constant returns to scale since 2001. Indeed, apple production in Beijing, 
Tianjin, Jiangsu, Anhui, Hubei, and Guizhou provinces exhibit increasing returns on average.

Technical progress is found to be Hicksian non-neutral, with the marginal productivity of planting area, labor and machine decreasing over time, while chemical pesticide, fertilizer, and irrigation are becoming more productive. A substitution relationship is found between planting area and irrigation, labor and machine, as well as for irrigation with pesticide and machine. In contrast, complementary relationships are found for planting area with labor and machine, labor with chemical fertilizer and irrigation, and fertilizer with irrigation.

Two indexes of environmental efficiency are estimated, one for an index based on pesticide input and another for the combination of pesticide and chemical fertilizer inputs. The empirical results show the estimated environmental efficiency in either case is lower than corresponding technical efficiency. Environmental efficiency is particularly low when calculated solely for pesticide input, ranging from 0.028 to 0.910 with a mean value of 0.603 . This result implies current pesticide use on China's apple production is inefficient and there is a great potential for reducing pesticide use and improving the efficiency. Encouragingly, all the estimates of efficiency have obvious increasing trends over time. By region, the highest environmental efficiency for pesticide input is in Southwest Cold Heights, while the highest environmental efficiency for the combination of pesticide and fertilizer is in Northwest Loess Plateau. However, the differences across regions in environmental efficiency are small.

Based on our empirical findings, some policy suggestions can be drawn. First, the government should pay more attention to the excessive use of pesticide, which has low environmental efficiency. Instead, apple growers may be encouraged to use of biopesticides, which are less detrimental to the environment. Second, farmer training and rural extension services should be strengthened so as to improve the use efficiency of pesticide and chemical fertilizer through raising farmers' environmental protection awareness and encouraging them to use more organic fertilizer and biopesticides or even physical methods of pest control. Third, government should take note of the complementary and substitute relationships between each inputs taking measures to reallocate input resources and improve technical and environmental efficiency.

\section{Acknowledgments}

The study was sponsored by the National Natural Science Foundation of China (71303188), the Ministry of Education of Humanities and Social Science Foundation (17YJA790003), and Social Science Foundation of Shaanxi Province (2017S018). The authors are grateful to all three anonymous referees and the handling editor Professor Hung-Hao Chang of this journal for useful comments and suggestions which materially improved the quality and presentation of this article. However, usual disclaimer applies. 


\section{Reference}

Abedullah, A., S. Kouser, and M. Qaim. 2015. "Bt cotton, Pesticide use and Environmental Efficiency in Pakistan." Journal of Agricultural Economics 66(1): 66-86.

Singbo, A.G., A.O. Lansink, and G. Emvalomatis. 2015. "Estimating Shadow Prices and Efficiency Analysis of Productive Inputs and Pesticide use of Vegetable Production." European Journal of Operation Research 245: 265-272.

Bai, X., X. Chen, and X. Huo. 2015. "The Impact of Climate Change on Apple Output and Total Factor Productivity in Major Apple Production Provinces." Agrotechnical Economics 8: 98-111. (in Chinese)

Battese, G.E., and T.J. Coelli. 1995. "A Model for Technical Inefficiency Effects in a Stochastic Frontier Production Function for Panel Data." Empirical Economics 20(2): 325-332.

Boggs, R.L. 1997. "Hazardous Waste Treatment Facilities: Modeling Production with Pollution as both an Input and an Output." PHD thesis, University of North Carolina, Chapel Hill.

Chen, J., M. Song, and L. Xu. 2015. "Evaluation of Environmental Efficiency in China using Data Envelopment Analysis." Ecological Indicators 52: 577-583.

Cropper, M.L., and W.E. Oates. 1992. "Environmental Economics: A Survey." Journal of Economic Literature 30: 675-740.

Cui, X., and Y. Zhang. 2014. "Agricultural Environmental Efficiency and Environmental TFP in China." China Rural Economics 8: 4-16. (in Chinese)

Edgardo, O.R., and P.A. Robert. 2018. "A Life Cycle Impact Assessment Method for Freshwater Eutrophication due to the Transport of Phosphorus from Agricultural Production." Journal of Cleaner Production 177: 474-482.

Färe, R., S. Grosskopf, C.A.K. Lovell, and C. Pasurka. 1989. "Multilateral Productivity Comparisons When Some Outputs are Undesirable: A Nonparametric Approach." Review of Economics and Statistics 71: 90-98.

Färe, R., S. Grosskopf, C. Lovell, and S. Yaisawarng. 1993. "Derivation of Shadow Prices for Undesirable Outputs: A Distance Function Approach." The Review of Economics and Statistics 75: 374-380.

Färe, R., S. Grosskopf, and C.A. Pasurka Jr. 2007. "Environmental Production Functions and Environmental Directional Distance Functions." Energy 32: 1055-1066.

Feng, T., and P. Wang. 2016. "Regional Difference in Pesticide Application Efficiency and its Influence Factors in China." Guizhou Agricultural Science 44(3): 76-82. (in Chinese)

Guo, J., X. Liu, Y. Zhang, J.L. Shen, W.X. Han, W.F. Zhang, P. Christie, et al. 2010. "Significant Acidification in Major Chinese Croplands." Science 327: 1008-1010.

Guo, Y., S. Yao, and X. Huo. 2013. "Evaluate the Technical Progress of Apple Production in China." Agrotechnical Economics 3: 54-61. (in Chinese)

Haynes, K.E., S. Ratick, W.M. Bowen, and J. Cummings-Saxton. 1993. "Environmental Decision Models: U.S. Experience and a New Approach to Pollution Management." Environment International 19: 261-275.

Ju, X.T., G.X. Xing, X.P. Chen, S.L. Zhang, L.J. Zhang, X.J. Liu, Z.L. Cui, et al. 2009. "Reducing Environmental Risk by Improving $\mathrm{N}$ Management in Intensive Chinese Agricultural Systems" Proceedings of the National Academy of Sciences of the United States of America 106(9): 3041-3046.

Lansink, A.O., and S. Reinhard 2004. "Investigating Technical Efficiency and Potential Technological Change in Dutch Pig Farming." Agricultural Systems 79: 353-467.

Li, C., J. Qiu, and C. Yin 2009. "Study on Calculating Losses of Cropland Degradation". Chinese Agricultural Science Bulletin 25(3): 230-235.

Li, G., L. Fan, and R. Min. 2011. "The Coordination of Agricultural Development with Environment and Resource." The Journal of Quantitative \& Technical Economics 10: 21-36.

Ma, L., S. Feng, P. Reidsma, F. Qu, and N. Heerink. 2014. “Identifying Entry Points to Improve Fertilizer use Efficiency in Taihu Basin, China." Land Use Policy 37(2): 52-59. 
Ma, Y., Z.H. Liu, B.D. Xi, X.S. He, Q.L. Li, Y.J. Qi, M.Y. Jin, et al. 2018. "Characteristics of Groundwater Pollution in a Vegetable Cultivation Area of Typical Facility Agriculture in a Developed City." Ecological Indicators in press. https://doi.org/10.1016/j.ecolind. 2018.10.056.

Muditha, K., and W. Clevo. 2017. "Agricultural Biodiversity and Farm Level Technical Efficiency: An Empirical Investigation." Journal of Forest Economics 29: 38-46.

NBSC (National Bureau of Statistics of China). China Rural Statistical Yearbook, China's Statistical Press, Beijing. 1993-2017. (in Chinese )

Piao, S., and J. Li. 2018. "Spatical-Temporal Differences of Regional Environmental Efficiency in China Based on Super Efficiency DEA Model." Journal of Arid Land Resource and Environment 32(4): 1-6. (in Chinese)

Pittman, R.W. 1983. "Multilateral Productivity Comparisons with Undesirable Outputs." Economic Journal 372: 883-891.

Reinhard, S., C.A.K. Lovell, and G.J. Thijssen. 1999. "Econometric Estimation of Technical and Environmental Efficiency: An Application to Dutch Dairy Farms." American Journal of Agricultural Economics 81: 44-60.

- 2000. "Environmental Efficiency with Multiple Environmentally Detrimental Variables: Estimated with SFA and DEA." European Journal of Operational Research 121: 287-303.

Sebnem, A. 2017. "Assessment of Groundwater and Soil Quality for Agricultural Purposes in Kopruoren Basin, Kutahya, Turkey." Journal of African Earth Sciences 131: 1-13.

Shi, J., J. Zhu, and J. Luan. 2015. "Fertilizer Use Efficiency of Wheat Production in China and its Determinants." Journal of Agrotechnical Economics 11: 69-78147. (in Chinese)

Tian, X., and S. Wang. 2016. "Environmental Efficiency and its Determinants Regarding China's Grain Production." Resource Science 38(11): 2106-2116. (in Chinese)

Tone, K. 2004. "Dealing with Undesirable Outputs in DEA: A Slacks-Based Measure (SBM) Approach." Presentation at the North American Productivity Workshop 2004, Toronto, Canada, 23-25 June.

Wang, Y., and N. Shen. 2016. "Agricultural Environmental Efficiency and Agricultural Environmental Kuznets Curve Based on Technological Gap: The Case of China." Polish Journal of Environmental Studies 25(3): 1293-1303.

Xiang, C., X. Jia, and J. Huang. 2012. "The Impact of Agricultural Technology Training for Farmers' Behaviour of Nitrogen Fertilizer use." Agrotechnical Economics 9: 4-10. (in Chinese)

Yuan, H., D. Yang, X. Yan, and L. Zhang. 2011. "Pesticide Efficiency and the Way to Optimize the Spray Application." Plant Protection 37(5): 14-20.

Zhang, T., and B. Xue. 2005. "Environmental Efficiency Analysis of China's Vegetable Production." Biomedical and Environmental Science 18: 21-30.

Zhang, W., F. Zhang, and L. Ma. 2007. "The Fertilizer Situation and Outlook in China." Presentation at the Sino-German International Research Training Group, Stuttgart, Germany, 13 November.

Zhou, Y., X. Zhang, X. Tian, X. Geng, P. Zhang, and B. Yan. 2015. "Technical and Environmental Efficiency of Hog Production in China- A Stochastic Frontier Production Function Analysis." Journal of Integrative Agriculture 14(6): 1069-1080. 